\title{
RE-EVALUASI PENERAPAN SISTEM PENGUMPULAN TOL ELEKTRONIS DI INDONESIA
}

\author{
Rikki Sofyan Rizal ${ }^{1}$, Rudy Hermawan $K^{2}$, TIti Liliani $\mathbf{S}^{3}$ \\ Program Studi Magister Sistem dan Teknik Jalan Raya Fakultas Teknik Sipil dan Lingkungan 1,2,3 \\ Institut Teknologi Bandung \\ Jl Ganesha no 10 Bandung \\ rikkisofyan@gmail.com ${ }^{1}$, ruherkar@yahoo.com ${ }^{2}$, titi_dupe@yahoo.com ${ }^{3}$
}

\begin{abstract}
Abstrak
Pada tahun 2007 untuk pertama kalinya diterapkan sistem pengumpulan tol elektronis untuk mengatasi permasalahan antrian panjang pada gerbang tol, akan tetapi penerapannya hanya terbatas pada beberapa ruas tol saja yang ada di Indonesia. Setelah itu tahun 2017 Menteri Pekerjaan Umum dan Perumahan Rakyat mengeluarkan peraturan Nomor 16/PRT/M/2017 tentang Transaksi Tol Nontunai di Jalan Tol, tanggal 31 Oktober 2017 untuk menerapkan sistem pengumpulan tol elektronis di seluruh gerbang tol di Indonesia. Untuk itu perlu dilakukan evaluasi terhadap penerapan sistem transaksi elektronis yang telah diterapkan saat ini. Dari analisis didapatkan dengan sistem elektronis ini waktu transaksi rata-rata untuk GTO 3 detik dan GSO 3,6 detik sehingga memenuhi SPM Jalan Tol yaitu kurang dari 5 detik. Untuk hasil perhitungan kapasitas, gardu nirsentuh memiliki kapasitas yang paling besar dibandingkan GTO dan GSO. Serta untuk analisis antrian dengan kapasitas gardu yang lebih besar dibandingkan dengan tingkat kedatangan kendaraan pada seluruh tipe gardu maka tidak terjadi antrian di gardu. Disisi lain dengan diterapkannya sistem pengumpulan tol elektronis saat ini $86 \%$ responden merasa puas dan ada beberapa keuntungan yang didapatkan oleh operator tol seperti menurunnya biaya operasi gardu. Kedepannya BUJT telah melakukan persiapan untuk penerapan transaksi berbasis nirsentuh dengan melakukan koordinasi antar operator tol mengenai sistem dan proses teknologi yang akan diterapkan.
\end{abstract}

Kata kunci :

Jalan tol, Sistem pengumpulan tol elektronis, Nirsentuh, Kapasitas, Antrian

\begin{abstract}
In 2007, for the first time, an electronic toll collection system was implemented to overcome queues in toll gate, however its application was only limited for several toll road segments in Indonesia. After that in 2017 the Minister of Public Works and Public Housing issued regulation Number 16 / PRT / M / 2017 concerning Cashless Transactions on Toll Road, in October $31^{\text {th }}$ 2017, to implement an electronic toll collection system in every toll gates in Indonesia. For this reason, it is necessary to evaluate the application of electronic transaction, systems that have been implemented at this time. From the analysis, it is obtained with this electronic system the average period of transaction for GTO is 3 seconds and GSO is 3.6 seconds, so that it meets the Toll Road SPM which is less than 5 seconds. For the results of capacity calculation, free flow booth has the highest capacity compared to the GTO and GSO. As well as for queuing analysis with booth capacity greater than the arrival rate of vehicles in all types of booth transaction, there is no queue at the booth transaction. On the other hand, with the implementation of the electronic toll collection system, currently $86 \%$ of respondents feel satisfied and there are several benefits obtained by toll operators such as the lower operating costs of booth. In the future BUJT has made preparations for the implementation of free flow transactions by coordinating between toll operators regarding the technology systems and processes to be implemented.
\end{abstract}

Keywords :

Toll Road, Electronics Toll Collection, Free flow, Capacity, Queue. 


\section{Pendahuluan}

Bertambahnya pengguna kendaraan di Indonesia menyebabkan arus lalu lintas khususnya di kota-kota besar sering menjadi macet. Karena kemacetan tersebut, masyarakat cenderung memilih jalan tol sebagai rute alternatif untuk mencapai tujuannya. Jalan tol dipilih sebagai rute alternatif karena memberi keandalan berupa kelancara lalu lintas yang lebih tinggi dari jalan biasa. Kelancaran lalu lintas di jalan tol dipengaruhi oleh waktu pelayanan (service time) yang diberikan kepada pengguna jalan saat melakukan transakti di gerbang tol. Namun pada kenyataannya, antrian panjang tidak dapat dihindari pada saat kendaraan akan masuk atau keluar dari gerbang tol, terutama pada waktu sibuk yang disebabkan karena lamanya waktu yang dibutuhkan pada saat transaksi di gebang tol.

Akan tetapi pada pelaksanaannya masih banyak kekurangan-kekurangan yang terjadi, penerapan sistem pengumpulan tol elektronis yang ada masih bersifat semi-automatic dimana masih dibutuhkan peran petugas pengumpul tol untuk menerima dan menempelkan kartu elektronis ke alat pemindai (scanner). Hanya beberapa gardu tol saja yang benarbenar menyediakan lajur khusus pembayaran tol elektronis dengan alat pembaca otomatis tanpa petugas pengumpul tol. Padahal dalam Peraturan Menteri Pekerjaan Umum dan Perumahan Rakyat Nomor 16/PRT/M/2017 pada Pasal 6 ayat 1 bagian b, akan diterapkan penyelenggaraan transaksi yang sepenuhnya menggunakan teknologi berbasis nirsentuh pada 31 Desember 2018.

Untuk itu perlu dilakukan evaluasi terhadap penerapan sistem transaksi elektronis yang telah diterapkan saat ini seperti waktu transaksi, antrian yang terjadi, respon pengguna jalan tol, serta keuntungan yang diperoleh oleh BUJT dan pengguna jalan tol yang dapat digunakan sebagai masukan untuk pihak-pihak yang terkait dalam penerapan sistem transaksi nirsentuh yang akan diterapkan nantinya

\section{KAJIAN LITERATUR}

\section{II.1 Sistem Pengumpulan Tol Elektronis (Electronic Toll Collection)}

Electronic Toll Collection (ETC) adalah suatu teknologi yang memungkinkan untuk melakukan pembayaran secara elektronik pada sistem pengumpulan tol. Sistem ETC dioperasikan dengan menggunakan alat komunikasi yang terpasang pada kendaraan dengan alat yang terpasang pada sisi jalan yang disebut Automatic Vehicle Identification (AVI), Automatic Vehicle Classification (AVC) dan Vehicle Enforcement System (VES). ETC pada dasarnya terbagi menjadi dua tipe, yaitu Semi Automatic dan Full Automatic. Beberapa keuntungan dari Sistem ETC (Chaundhary, 2003) :

- Meningkatkan Kapasitas Gardu Tol

- Mengurangi Antrian

- Menghemat Biaya Operasi Transaksi

- Mengurangi Kesalahan Petugas Pengumpul Tol

\section{II.2 Analisis Antrian}

Antrian pada dasarnya terjadi karena proses pergerakan arus lalu lintas terganggu oleh adanya suatu kegiatan pelayanan yang harus dilalui, seperti misalnya antrian kendaraan yang terbentuk di depan gerbang tol terjadi karena pergerakan arus kendaraan tersebut terpaksa harus terganggu oleh adanya kegiatan pengambilan dan/atau pengembalian (pembayaran) kartu tol. Kegiatan tersebut akan menyebabkan gangguan pada proses pergerakan arus kendaraan sehingga mengakibatkan terjadinya antrian kendaraan dimana pada suatu kondisi, antrian tersebut akan mengakibatkan permasalahan baik untuk pengguna maupun pengelola.

Dalam sistem antrian terdapat komponen utama, yaitu tingkat kedatangan, tingkat pelayanan, jumlah fasilitas pelayanan, kapasitas pelayanan, dan aturan pelayanan atau disiplin antrian.

\section{- Tingkat Kedatangan}

Tingkat kedatangan yang dinyatakan dengan notasi $\lambda$ adalah jumlah kendaraan atau manusia yang bergerak menuju satu atau beberapa tempat pelayanan dalam satu satuan waktu tertentu, biasa dinyatakan dalam satuan kendaraan/jam atau orang/menit. (Tamin, 2008). 


\section{- Tingkat Pelayanan}

Tingkat pelayanan yang dinotasikan dengan $\mu$ adalah julah kendaraan atau manusia yang dapat dilayani oleh satu tempat pelayanan dalam satu satuan waktu tertentu, biasa dinyatakan dalam satuan kendaraan/jam atau orang/menit.

\section{- Disiplin Antrian}

Disiplin antrian menunjukkan aturan untuk memilih anggota satu anggota dari antrian untuk dilayani, misalanya memeilih yang datang terlebih dahulu (first come first serve), acak (random service), prioritas tertentu (priority).

Disiplin antrian FIFO sering digunakan dibidang transportasi dimana orang dan atau kendaraan yang pertama tiba pada suatu tempat pelayanan akan dilayani pertama. Sebagai contoh disiplin antrian FIFO adalah antrian kendaraan yang terbentuk di pintu gerbang tol (Tamin, 2008).

\section{- Parameter Antrian}

Terdapat empat parameter utama yang selalu digunakan dalam menganalisis antrian, yaitu : Ls, Lq, Ws, dan Wq. Definisi dari setiap parameter tersebut adalah:

Ls= Jumlah kendaraan atau orang dalam sistem (kendaraan atau orang per satuan waktu)

$\mathrm{Lq}=$ Jumlah kendaraan atau orang dalam antrian (kendaraan atau orang per satuan waktu)

Ws= Waktu kendaraan atau orang dalam sistem (satuan waktu)

$\mathrm{Wq}=$ Waktu kendaraan atau orang dalam antrian (satuan waktu)

Persamaan berikut merupakan persamaan yang dapat digunakan untuk menghitung Ls, Lq, Ws, dan Wq untuk antrian sederhana (single sever model) dengan kedatangan berdistribusi poisson dan waktu pelayanan berdistribusi eksponensial.

$$
\begin{aligned}
& L_{g}=\frac{x}{(\mu-\lambda)} \\
& L_{q}=\frac{x^{2}}{(\mu(\mu-\lambda))} \\
& W_{s}=\frac{1}{(\mu-\lambda)}
\end{aligned}
$$

$$
W_{q}=\frac{x}{\mathbb{q}(\mu-x))}
$$

\section{- MODEL ANTRIAN}

Disisi lain apabila waktu kedatangan dan pelayanan pada masing-masing kendaraan diketahui, maka kedua distribusi baik distribusi kedatangan maupun distribusi pelayanan adalah deterministik.

Selain itu pada saat rasio tingkat kedatangan $\left({ }^{\lambda}\right)$ dengan tingkat pelayanan $\left(^{\mu}\right)$ lebih dari 1 maka hanya dapat digunakan analisis deterministik makroskopis simulasi.

Metode simulasi antrian deterministik makroskopis di gerbang tol dikembangkan oleh F.B. Lin dan C.W.Su, telah menunjukkan konsistensi dalam pemecahan masalah antrian di gerbang tol.

Berdasarkan metode Lin $\& \mathrm{Su}$, untuk suatu nilai panjang antrian rata-rata, waktu rata-rata didalam sistem dapat diestimasikan sebagai berikut:

$$
\begin{array}{ll}
\mathrm{T}=\frac{1605+2205 \mathrm{~L}}{c} & \mathrm{~L} \leq 15 \\
\mathrm{~T}=\frac{9748+2776 \mathrm{~L}}{c} & \mathrm{~L}>15
\end{array}
$$

dimana:

$\mathrm{T}=$ waktu rata-rata didalam sistem (detik)

$\mathrm{L}=$ panjang rata-rata antrian (kendaraan)

$\mathrm{C}=$ kapasitas gerbang $($ kendaraan/jam)

Hubungan antara panjang rata-rata antrian dengan kapasitas gerbang dan rasio volume-kapasitas dapat diekspresikan sebagai berikut :

$$
\begin{aligned}
& \mathrm{L}=0 \quad, \text { jika } \frac{\pi}{\mu} \leq 0.5 \\
& \mathrm{~L}=7 \frac{\lambda}{\mu}-3.5 \quad, \text { jika } 0.5 \leq \frac{\lambda}{\mu} \leq 0.93 \\
& \mathrm{~L}=3[1+6.29(\lambda / \mu-0.93)(\mu / 360-1)] \times\left[1+\mathrm{t}(14 \lambda / \mu-13)^{2}\right] \\
& \quad, \text { jika } \frac{\lambda}{\mu} \geq 0.93 \\
& \text { dimana: } \\
& \frac{\lambda}{\mu}=\text { rasio volume - kapasitas }
\end{aligned}
$$


$\mathrm{t}=$ durasi arus $(\mathrm{jam})$

\section{II.3 Hubungan Matematis Kecepatan, Kerapatan, dan Volume}

Model Greenshield. Greenshield merumuskan bahwa hubungan matematis antara Kecepatan Kerapatan (S - D) diasumsikan linear, dari asumsi tersebut dihasilkanlah persamaan dari hubungan Kecepetan, Kerapatan dan Volume sebagai berikut.

Hubungan S - D menghasilkan

$$
S=S_{f f}-\frac{s_{f f}}{D_{j}} \cdot D
$$

Hubungan V - D menghasilkan

$$
V=D \cdot S_{f f}-\frac{s_{f f}}{D_{j j}} \cdot D^{2}
$$

Hubungan $\mathrm{V}-\mathrm{S}$ menghasilkan

$$
V=D \cdot S-\frac{D_{j}}{S_{f f}} \cdot S^{2}
$$

Untuk mendapatkan volume, kecepatan dan kerapatan yang maksimum dapat menggunakan Persamaan (12), (13) dan (14).

$$
\begin{aligned}
V_{M} & =\frac{D_{j} s_{f f}}{4} \\
S_{M} & =\frac{s_{f f}}{2} \\
D_{M} & =\frac{D_{I}}{2}
\end{aligned}
$$

dimana:

VM kapasitas atau volume maksimum (kendaraan/jam)

SM kecepatan pada kondisi volume lalu lintas maksimum $(\mathrm{km} / \mathrm{jam})$

DM kerapatan pada kondisi volume lalu lintas maksimum (kendaraan/jam

Dj kerapatan pada kondisi lalu lintas macet total (kendaraan / km)

$\mathrm{S}_{\mathrm{ff}} \quad$ kecepatan pada kondisi volume lalu lintas sangat rendah atau pada kondisi kerapatan mendekati 0 (nol) atau kecepatan arus bebas $(\mathrm{km} / \mathrm{jam})$

\section{II.4 Standar Pelayanan Minimum (SPM) Jalan Tol}

Menurut Permen PU Nomor 16/PRT/M/2014 Standar Pelayanan Minimum jalan tol adalah ukuran yang harus dicapai dalam pelaksanaan penyelenggaraan jalan tol. Besaran ukuran tersebut dievaluasi secara berkala berdasarkan hasil

\begin{tabular}{|c|c|c|c|}
\hline \multirow{2}{*}{$\begin{array}{l}\text { Substansi } \\
\text { Pelayanan }\end{array}$} & \multicolumn{3}{|c|}{ Standar Pelayanan Minimum } \\
\hline & Indikator & Cakupan/Lingkup & Tolak Ukur \\
\hline \multirow{3}{*}{ Aksesibilitas } & $\begin{array}{c}\text { - Kecepatan } \\
\text { Transaksi } \\
\text { rata-rata }\end{array}$ & $\begin{array}{l}\text { - GT0 } \\
\text { •Gardu Tol } \\
\text { ambil kartu }\end{array}$ & $\begin{array}{l}\text { - Maksimal } 4 \text { detik } \\
\text { setiap kendaraan }\end{array}$ \\
\hline & & $\begin{array}{c}\text { - Gardu tol } \\
\text { transaksi }\end{array}$ & $\begin{array}{l}\text { - Maksimal } 5 \text { detik } \\
\text { setiap kendaraan }\end{array}$ \\
\hline & $\begin{array}{l}\text { - Jumlah } \\
\text { antrian } \\
\text { kendaraan }\end{array}$ & - Gardu Tol & $\begin{array}{l}\text { - Maksimal } 10 \\
\text { kendaraan per } \\
\text { gardu dalam } \\
\text { kondisi normal }\end{array}$ \\
\hline
\end{tabular}
pengawasan fungsi dan manfaat Standar Pelayanan Minimal Jalan Tol untuk meningkatkan pelayanan kepada pengguna jalan.

Tabel 1. Standar Pelayanan Minumum Jalan Tol berkaitan dengan Aksesibilitas

Judul bab ini dapat disesuaikan dengan kebutuhan, misalnya dapat berupa "Tinjauan Pustaka", atau "Landasan Teori", atau dapat juga berupa "Penelitian Terkait". Bab ini memuat landasan teori atau ulasan singkat teori yang dibutuhkan untuk menunjang pelaksanaan penelitian, baik berupa kajian literature maupun kajian atas penelitian yang sebelumnya. Sitasi / rujukan yang digunakan adalah format APA Fifth Edition seperti contoh (Fruhling \& Lee, 2005).

\section{Metodologi Penelitian}

Secara garis besar penelitian yang akan dilaksanakan dibagi menjadi beberapa tahapan, diantaranya adalah :

\section{III.1 Tahap Persiapan}

Pada tahapan ini ditetapkan lokasi studi yang akan dikaji. Adapun lokasi jalan tol yang akan di kaji yaitu Jalan Tol Jakarta - Tangerang - Cengkareng yang dikelola oleh PT Jasa Marga Cabang JTC. Untuk gerbang yang ditinjau pada penelitian ini yaitu Gerbang Tol Cililitan dan Gerbang Tol Kapuk. 
Pemilihan lokasi penelitian ini karena hanya pada gerbang tol tersebut yang memiliki 3 sistem pengumpulan tol elektronis yang berbeda (GTO, GSO, dan Nirsentuh) dibandingkan dengan gerbang tol lain yang hanya memiliki 2 sistem pengumpulan tol saja (GTO dan GSO). Selain itu dengan ditentukannya lokasi gerbang tol dengan karakteristik yang sama yaitu menerapkan sistem transaksi terbuka serta merupakan jalan tol dalam kota, diharapkan hasil yang didapatkan tidak akan jauh berbeda. Adapun untuk pengamatan masing-masing gerbang diambil 4 gardu sebagai sample yaitu 2 Gardu GTO khusus Golongan I, 1 Gardu GTO untuk semua golongan serta 1 Gardu Nirsentuh.

\section{III.2 Tahapa Pengumpulan Data dan Pengolahan Data}

Pengumpulan data pada tahap ini dibagi menjadi 2 yaitu pengumpulan data primer dan data sekunder.

Gambaran umum data-data yang diperlukan dalam penelitian ini beserta cara pengumpulan dan tujuan penggunaannya tercatat pada tabel berikut :

Tabel 2. Daftar Informasi Data Penelitian

\begin{tabular}{|l|l|l|}
\hline \multicolumn{1}{|c|}{ Macam Informasi/Data } & Jenis Data & \multicolumn{1}{c|}{ Metode Pengumpulan Data } \\
\hline $\begin{array}{l}\text { Tingkat Kedatangan Kendaraan } \\
(\lambda)\end{array}$ & Primer & Survey Langsung \\
\hline Waktu Transaksi & Primer & Survey Langsung \\
\hline Waktu Tempuh & Primer & Survey Langsung \\
\hline Respon Pengguna Jalan Tol & Primer & Kuisioner \\
\hline Data nilai waktu (time value) & Sekunder & $\begin{array}{l}\text { Diambil dari data yang dimiliki } \\
\text { BUJT }\end{array}$ \\
\hline
\end{tabular}

\section{III.3 Tahap Analisis dan Pembahasan}

Analisa terhadap data dalam penelitian ini dilakukan berdasarkan beberapa tahapan analisis. Tahapan keseluruhan analisa yang dilakukan secara sistematis dibagi menjadi tiga bagian. Analisis pertama mengenai analisis antrian dan waktu pelayanan, bagian kedua menganalisis respon dari pengguna jalan tol dan operator jalan tol serta bagian ketiga menganalisis keuntungan yang didapatkan oleh pengguna dan operator jalan tol.

\section{III.4 Tahap Penyempurnaan (Penarikan kesimpulan dan saran).}

Dari hasil analisis yang telah dilakukan dapat ditarik beberapa kesimpulan mengenai antrian yang terjadi, respon dari pengguna jalan tol, serta biaya operasional dan pemeliharaan dari sitem transaksi elektronis ini. Kesimpulan yang diperoleh nantinya dapat digunakan oleh operator jalan tol sebagai tolak ukur dalam penerapan sistem transaksi elektonis di masa yang akan datang. Selain itu pada tahap ini diberikan pula saran-saran yang diperlukan untuk penelitian selanjutnya.

\section{Analisis dan Perancangan}

\section{IV.1 Waktu Transaksi}

Survei waktu transaksi dilakukan pada hari Senin, 7 Mei 2018 untuk Gerbang Tol Cililitan. Untuk survey waktu transaksi pada Gerbang Tol Kapuk dilakukan pada hari Senin, 13 Mei 2018. Pada Tabel 3 disajikan rekapitulasi survei waktu transaksi yang terjadi.

Tabel 3. Rekapitulasi Hasil Survei Waktu Transaksi di Gerbang Tol Cililitan dan Gerbang Tol Kapuk

\begin{tabular}{|c|c|c|c|c|c|c|}
\hline \multirow{2}{*}{ Gerbang } & \multirow{2}{*}{$\begin{array}{c}\text { No } \\
\text { Gardu }\end{array}$} & \multirow{2}{*}{$\begin{array}{l}\text { Tipe } \\
\text { Gardu }\end{array}$} & \multirow{2}{*}{$\begin{array}{l}\text { Jumlah } \\
\text { Sampel }\end{array}$} & \multicolumn{2}{|c|}{$\begin{array}{l}\text { Waktu Transaksi } \\
\text { (T2) (Detik) }\end{array}$} & \multirow{2}{*}{ Keterangan } \\
\hline & & & & $\begin{array}{l}\text { Rata- } \\
\text { rata }\end{array}$ & Standar & \\
\hline \multirow{3}{*}{ Cililitan } & 7 & GTO & 80 & 3,0 & \multirow{3}{*}{5} & $\begin{array}{c}\text { Memenuhi } \\
\text { standar }\end{array}$ \\
\hline & 5 & GTO & 80 & 3,0 & & $\begin{array}{l}\text { Memenuhi } \\
\text { standar }\end{array}$ \\
\hline & 13 & GSO & 150 & 3,5 & & $\begin{array}{l}\text { Memenuhi } \\
\text { standar }\end{array}$ \\
\hline \multirow{3}{*}{ Kapuk } & 7 & GTO & 80 & 3,0 & 5 & $\begin{array}{c}\text { Memenuhi } \\
\text { standar }\end{array}$ \\
\hline & 8 & GTO & 80 & 2,9 & & $\begin{array}{l}\text { Memenuhi } \\
\text { standar }\end{array}$ \\
\hline & 9 & GSO & 150 & 3,7 & & $\begin{array}{c}\text { Memenuhi } \\
\text { standar }\end{array}$ \\
\hline
\end{tabular}

Dari hasil tersebut dapat terlihat bahwa untuk waktu transaksi pada GTO lebih cepat dibandingkan GSO. Bila dibandingkan dengan SPM Jalan Tol, waktu transaksi GTO maupun GSO sudah memenuhi standar yaitu dibawah 5 detik.

\section{IV.2 Waktu Pelayanan}

Hasil dari analisis waktu pelayanan gardu pada Gerbang Tol Cililitan dan Gerbang Tol Kapuk disajikan pada Tabel 4. 
Tabel 4. Waktu Pelayanan Gardu Rata rata Pada Gerbang Tol Cililitan dan Gerbang Tol Kapuk

\begin{tabular}{|c|c|c|c|c|c|c|}
\hline Gerbang & $\begin{array}{c}\text { No } \\
\text { Gardu }\end{array}$ & $\begin{array}{c}\text { T1 } \\
\text { (Detik) }\end{array}$ & $\begin{array}{c}\text { T2 } \\
\text { (Detik) }\end{array}$ & $\begin{array}{c}\text { T3 } \\
\text { (Detik) }\end{array}$ & $\begin{array}{c}\text { Waktu } \\
\text { Pelayanan } \\
\text { T1+T2+T3 }\end{array}$ & $\begin{array}{c}\text { Waktu } \\
\text { Pelayanan } \\
\text { Rata-rata } \\
\text { (detik) }\end{array}$ \\
\hline \multirow{3}{*}{ Cililitan } & 7 & 4,1 & 3,0 & 4,1 & 11,2 & \multirow{2}{*}{11,3} \\
\cline { 2 - 6 } & 5 & 3,9 & 3,0 & 4,1 & 11,0 & \multirow{2}{*}{11,3} \\
\cline { 2 - 6 } & 13 & 4,0 & 3,5 & 4,4 & 11,8 & \\
\hline \multirow{3}{*}{ Kapuk } & 7 & 4,0 & 3,0 & 4,0 & 11,0 & \multirow{2}{*}{11,4} \\
\cline { 2 - 6 } & 8 & 4,1 & 2,9 & 3,7 & 10,8 & \multirow{2}{*}{} \\
\cline { 2 - 6 } & 9 & 4,0 & 3,7 & 4,8 & 12,5 & \\
\hline
\end{tabular}

Bila dilihat dari waktu pelayanan yang ada, waktu ketika kendaraan sebelum transaksi (T1) dan waktu kendaraan setelah transaksi (T3) lebih besar dibandingkan dengan waktu transaksi (T2). Hal ini dipengaruhi oleh beberapa faktor seperti kesiapan pengemudi dan karakteristik jenis kendaraan (golongan kendaraan) yang berpengaruh terhadap akselerasi dan deselerasi kendaraan pada saat berada di pintu pelayanan.

Dari hasil uji normalitas yang dilakukan dengan menggunakan SPSS, untuk waktu pelayanan Gerbang Tol Cililitan pada gardu 7, 5 dan 13 serta Gerbang Tol Kapuk pada Gardu 7, 8 dan 9 tidak berdistribusi eksponensial, karena hasil P value (Assymp. Sig. (2tailded)) yang didapatkan $=0$, sehingga nilai $\mathrm{P}$ value $<\alpha=0,05$ dengan demikian H0 ditolak.

\section{IV.3 Analisis Kapasitas Gardu}

\section{- Kapasitas Gardu GTO dan GSO}

Perhitungan kapasitas gardu untuk GTO dan GSO dilakukan pada masing-masing gerbang dengan menggunakan rumus sebagai berikut:

Kapasitas Gardu $=\frac{3600}{\text { Waktu Transaksi p pelayanan }}$

Hasil analisis perhitungan kapasitas gardu pada Gerbang Tol Cililitan dan Gerbang Tol Kapuk disajikan pada Tabel IV.4 dengan berdasarkan waktu pelayanan adalah waktu transaksi.
Tabel 5. Kapasitas Gardu GTO serta GSO pada Gerbang Tol Cililitan dan Gerbang Tol Kapuk berdasarkan waktu pelayanan dan waktu transaksi.

\begin{tabular}{|c|c|c|c|c|c|c|c|}
\hline Gerbang & $\begin{array}{c}\text { No } \\
\text { Gardu }\end{array}$ & $\begin{array}{c}\text { WP } \\
(\mathrm{T} 1+\mathrm{T} 2 \\
+\mathrm{T} 3)\end{array}$ & $\begin{array}{l}\text { Kap. } \\
\text { Gardu } \\
\text { (Kend } \\
\text { /Jam) } \\
\end{array}$ & $\begin{array}{c}\text { Rata-rata } \\
\text { Kapasitas } \\
\text { Gardu } \\
\text { (Kend/Jam) } \\
\end{array}$ & $\begin{array}{c}\text { Waktu } \\
\text { Transaksi } \\
\text { (T2) }\end{array}$ & $\begin{array}{c}\text { Kap. } \\
\text { Gardu } \\
\text { (Kend } \\
\text { /jam) }\end{array}$ & $\begin{array}{c}\text { Rata-rat } \\
\text { Kapasita } \\
\text { Gardu } \\
\text { (Kend/Jal }\end{array}$ \\
\hline \multirow{3}{*}{ Cililitan } & 7 GTO & 11,2 & 323 & \multirow{3}{*}{318} & 3 & 1200 & \multirow{3}{*}{1080} \\
\hline & 5 GTO & 11,0 & 327 & & 3 & 1200 & \\
\hline & 13 GSO & 11,8 & 305 & & 3,5 & 1028 & \\
\hline \multirow{3}{*}{ Kapuk } & 7 GTO & 11,0 & 327 & \multirow{3}{*}{317} & 3 & 1200 & \multirow{3}{*}{1126} \\
\hline & 8 GT0 & 10,8 & 333 & & 2,9 & 1241 & \\
\hline & 9 GT0 & 12,5 & 289 & & 3,7 & 973 & \\
\hline
\end{tabular}

Dari hasil analisis yang telah dilakukan, kapasitas gardu yang didapatkan dengan menggunakan waktu pelayanan lebih kecil dibandingkan dengan menggunakan waktu transaksi. Sehingga kapasitas rata-rata untuk gardu dengan menggunakan waktu transaksi tiga kali lebih besar dibandingkan dengan menggunakan waktu pelayanan.

\section{- Kapasitas Gardu Nirsentuh \\ - Kapasitas Gardu dengan MKJI}

Pada perhitungan kapasitas untuk gardu nirsentuh ini didapatkan dengan menggunakan hubungan kecepatan-arus-kerapatan serta dengan mengasumsikan gerbang sama seperti ruas jalan bebas hambatan dalam MKJI 1997 menggunakan model Rejim Tunggal dan ditetapkan kecepatan arus bebas $88 \mathrm{~km} /$ jam serta lebar jalan 2,9 meter (faktor lebar jalan -3). Sementara itu data yang diperoleh dari lapangan berupa kecepatan setempat (spot speed) diubah menjadi kecepatan rata-rata ruang (space mean speed). Dari data yang ada di plotkan kedalam model MKJI 1997, sehingga nantinya didapatkan kapasitas untuk gardu nirsentuh ini. Berikut ditampilkan hasil perhitungan kecepatan rata-rata berdasarkan ruang Gerbang Tol Cililitan dan Gerbang Tol Kapuk pada Tabel 6 dan Tabel 7 
Tabel 6. Kecepatan rata-rata berdasarkan ruang (space mean speed) pada Gerbang Tol Cililitan

\begin{tabular}{|c|c|c|c|c|}
\hline \multirow{2}{*}{ No } & Waktu & Arus & $\begin{array}{c}\text { Kecepatan } \\
\text { Rata-rata } \\
\text { Ruang }\end{array}$ & Kerapatan \\
\cline { 2 - 5 } & menit & Kend/Jam & Km/Jam & Kend/Km \\
\hline 1 & $0-10$ & 54 & 17,68 & 3,05 \\
\hline 2 & $10-20$ & 78 & 19,21 & 4,06 \\
\hline 3 & $20-30$ & 54 & 18,41 & 2,93 \\
\hline 4 & $30-40$ & 60 & 18,12 & 3,31 \\
\hline 5 & $40-50$ & 78 & 17,62 & 4,43 \\
\hline 6 & $50-60$ & 54 & 18,28 & 2,95 \\
\hline 7 & $60-70$ & 42 & 17,49 & 2,40 \\
\hline 8 & $70-80$ & 90 & 18,09 & 4,97 \\
\hline 9 & $80-90$ & 72 & 18,78 & 3,83 \\
\hline 10 & $90-100$ & 84 & 17,90 & 4,69 \\
\hline 11 & $100-110$ & 60 & 16,99 & 3,53 \\
\hline 12 & $110-120$ & 48 & 19,35 & 2,48 \\
\hline \multicolumn{2}{|c|}{ Total } & $\mathbf{7 7 4}$ & $\mathbf{2 1 7 , 9 1 6}$ & $\mathbf{4 2 , 6 5 5}$ \\
\hline \multicolumn{2}{|c|}{ Rata-rata } & $\mathbf{6 4 , 5 0 0}$ & $\mathbf{1 8 , 1 6 0}$ & $\mathbf{3 , 5 5 5}$ \\
\hline
\end{tabular}

Tabel 7. Kecepatan rata-rata berdasarkan ruang (space mean speed) pada Gerbang Tol Kapuk

\begin{tabular}{|c|c|c|c|c|}
\hline \multirow{2}{*}{ No } & Waktu & Arus & $\begin{array}{c}\text { Kecepatan } \\
\text { Ruang } \\
\text { Rata-rata }\end{array}$ & Kerapatan \\
\cline { 2 - 5 } & menit & Kend/Jam & Km/Jam & Kend/Km \\
\hline 1 & $0-10$ & 126 & 17,41 & 7,24 \\
\hline 2 & $10-20$ & 90 & 19,58 & 4,60 \\
\hline 3 & $20-30$ & 102 & 16,59 & 6,15 \\
\hline 4 & $30-40$ & 60 & 15,60 & 3,85 \\
\hline 5 & $40-50$ & 84 & 18,17 & 4,62 \\
\hline 6 & $50-60$ & 114 & 19,27 & 5,92 \\
\hline 7 & $60-70$ & 66 & 18,74 & 3,52 \\
\hline 8 & $70-80$ & 90 & 17,22 & 5,23 \\
\hline 9 & $80-90$ & 162 & 17,36 & 9,33 \\
\hline 10 & $90-100$ & 102 & 18,92 & 5,39 \\
\hline 11 & $100-110$ & 66 & 17,48 & 3,78 \\
\hline 12 & $110-120$ & 84 & 18,19 & 4,62 \\
\hline \multicolumn{2}{|c|}{ Total } & $\mathbf{1 1 4 6}$ & $\mathbf{2 1 4 , 5 1 0}$ & $\mathbf{6 4 , 2 3 7}$ \\
\hline \multicolumn{2}{|c|}{ Rata-rata } & $\mathbf{9 5 , 5 0 0}$ & $\mathbf{1 7 , 8 7 6}$ & $\mathbf{5 , 3 5 3}$ \\
\hline
\end{tabular}

Dari tabel tersebut dengan kecepatan ruang ratarata pada Gerbang Tol Cililitan dan Gerbang Tol Kapuk adalah 18,160 km/jam dan 17,876 km/jam bila di plotkan kedalam model MKJI 1997 maka didapatkan kapasitas untuk Gerbang Tol Cililitan 1321 kendaraan/jam dan Gerbang Tol Kapuk 1305 kendaraan/jam. Bila dibandingkan dengan hasil penelitian sebelumnya dengan metode yang sama untuk kecepatan ruang rata-rata $17 \mathrm{~km} / \mathrm{jam}$ ketika kendaraan melintasi gardu nirsentuh kapasitas yang dihasilkan adalah 1450 kendaran/jam (Hianto, 2015). Dengan demikian hasil yang didapatkan mendekati dengan penelitian terdahulu.

\section{- Kapasitas Gardu dengan Greenshield}

Kapasitas Gardu Tol Nirsentuh didapatkan dengan menggunakan metode Greenshield dengan mengasumsikan gerbang tol sama seperti ruas jalan. Data yang diperoleh dari lapangan berupa kecepatan setempat (spot speed) diubah menjadi kecepatan ratarata berdasarkan ruang (space mean speed). Dari data tersebut dibuatlah grafik hubungan kecepatan ruang rata-rata dengan kerapatan dengan menggunakan metode menggunakan regresi linear.

Dari Tabel 6. dan Tabel 7. setelah dilakukan perhitungan dengan regresi linear, didapatkan hasil pada Tabel 8 berikut :

Tabel 8. Hasil Analisis Kapasitas dengan Metode Greendshield pada Gerbang Tol Cililitan dan Gerbang Tol Kapuk

\begin{tabular}{|c|c|c|}
\hline \multirow{2}{*}{ Uraian } & \multicolumn{2}{|l|}{ Gerbang Tol } \\
\hline & Cililitan & Kapuk \\
\hline A & 18,428 & 18,284 \\
\hline $\mathrm{B}$ & $-0,0075$ & $-0,076$ \\
\hline R Square & 0,0081 & 0,011 \\
\hline $\mathrm{S}_{\mathrm{ff}}$ & $18,428 \mathrm{~km} / \mathrm{jam}$ & $18,284 \mathrm{~km} / \mathrm{jam}$ \\
\hline $\begin{array}{l}\text { Hubungan } \\
\text { Kecepatan - } \\
\text { Kerapatan }\end{array}$ & $\begin{array}{c}S=18,428- \\
0,0075 \mathrm{D}\end{array}$ & $\begin{array}{c}\mathrm{S}=18,284- \\
0,076 \mathrm{D}\end{array}$ \\
\hline $\begin{array}{c}\text { Hubungan Arus - } \\
\text { Kerapatan }\end{array}$ & $\begin{array}{c}\mathrm{V}=18,428 \mathrm{D}- \\
0,0075 \mathrm{D}^{2}\end{array}$ & $\begin{array}{c}\mathrm{V}=18,284 \mathrm{D}- \\
0,076 \mathrm{D}^{2}\end{array}$ \\
\hline $\begin{array}{l}\text { Hubungan Arus - } \\
\text { Kecepatan }\end{array}$ & $\begin{array}{c}\mathrm{V}=244,080 \mathrm{~S}- \\
0,0075 \mathrm{~S}^{2}\end{array}$ & $\begin{array}{c}\mathrm{V}=239,88 \mathrm{~S}- \\
0,076 \mathrm{~S}^{2}\end{array}$ \\
\hline$D_{M}($ Kend $/ \mathrm{km})$ & 122.04 & 119,94 \\
\hline$S_{M}(\mathrm{~km} / \mathrm{jam})$ & 9,214 & $9,149,14$ \\
\hline$V_{M}($ Kend/jam $)$ & 1124,48 & 1096,50 \\
\hline
\end{tabular}

Dari hasil analisis tersebut maka kapasitas gardu nirsentuh pada Gerbang Tol Cililitan adalah 1124,48 kendaraan/jam dan pada Gerbang Tol Kapuk adalah

Rikki Sofyan Rizal, Rudy Hermawan K, Titi Liliani S 
1096,5 kendaraan/jam. Bila dibandingkan dengan hasil yang didapat dari metode MKJI, kapasitas berdasarkan metode MKJI lebih besar dibandingkan dengan metode Greendshield. Hal ini terjadi karena pada metode MKJI model yang digunakan bukan berasal dari hasil data yang didapatkan, melainkan berasal dari standar model ruas jalan bebas hambatan (model rejim tunggal) sehingga pada saat diplotkan, data tidak menyebar pada model tersebut sehingga model MKJI tidak cocok untuk digunakan dalam analisis perhitungan kapasitas gardu nirsentuh. Sementara dengan metode Greenshield, kapasitas didapatkan berdasarkan data yang dimodelkan dengan regresi linear sehingga ketika data diplotkan dalam model, data tersebut berada dalam trendline model tersebut.

\section{IV.4 Model Antrian Sederhana}

\section{- Gerbang Tol Cililitan}

Pada Gerbang Tol Cililitan, dari hasil pengamatan didapatkan tingkat kedatangan tertinggi ( $\lambda$ ) yaitu 5852 kendaraan/jam. Dari kedatangan tersebut terdapat kedatangan kendaraan yang menggunakan gardu nirsentuh $\left(\lambda_{n}\right)$ sebesar 66 kendaraan/jam, sehingga kedatangan kendaraan untuk GTO dan GSO $\left(\lambda_{0}\right)$ adalah 5786 kendaraan/jam. Dengan mengasumsikan tingkat kedatangan kendaraan untuk GTO dan GSO terbagi merata (17 gardu), maka kedatangan kendaraan pada GTO dan GSO per gardu adalah 340 kendaraan/jam. Tingkat pelayanan $(\mu)$ dari masing-masing GTO, GSO, dan Gardu Nirsentuh adalah 325, 305 dan 711 kendaraan/jam. Dari varaibel-variabel tersebut dilakukan analisis, berikut contoh perhitungan analisis model antrian sederhana pada GTO.

$$
\begin{aligned}
\mathrm{Ls} & =\lambda /(\mu-\lambda) \\
& =340 /(315-340) \quad=-13,425 \text { kendaraan } \\
\mathrm{Lq} & =\lambda^{2} / \mu(\mu-\lambda) \\
& =340^{2} /(315(315-340)=-14,505 \text { kendaraan } \\
\mathrm{Wq} & =1 /(\mu-\lambda) \\
& =1 /(315-340) \quad=-0,039 \text { detik } \\
\mathrm{Ws} & =\lambda / \mu(\mu-\lambda) \quad \\
& =340 /(315(315-340)=-0,043 \text { detik }
\end{aligned}
$$

\begin{tabular}{|c|c|c|c|c|c|c|}
\hline \multirow[b]{2}{*}{ No } & \multirow{2}{*}{$\begin{array}{l}\text { Nama } \\
\text { Gardu }\end{array}$} & Ls & $\mathbf{L q}$ & Ws & Wq & \multirow[b]{2}{*}{ Keterangan } \\
\hline & & kend & kend & detik & detik & \\
\hline 1 & 2 & & 4 & 5 & 6 & 7 \\
\hline 1 & GTO & $-22,169$ & $-23,216$ & $-0,068$ & $-0,065$ & Kapasitas \\
\hline 2 & GSO & $-9,627$ & $-10,743$ & $-0,032$ & $-0,028$ & Berdasarkan \\
\hline 3 & Nirsentuh & 0,053 & 0,003 & 0,000 & 0,001 & Waktu Pelayanan \\
\hline 4 & GTO & 0,395 & 0,112 & 0,000 & 0,000 & Kapasitas \\
\hline 5 & GSO & 0,494 & 0,163 & 0,000 & 0,001 & rdacarkan \\
\hline 6 & Nirsentuh & 0,053 & 0,003 & 0,000 & 0.001 & \\
\hline
\end{tabular}

Berikut ditampilkan hasil analisis antrian dengan metode sederhana pada Tabel 8 .

Tabel 8. Hasil Analisis Perhitungan Model Antrian Sederhana Pada Gerbang Tol Cililitan dengan Menggunakan Kapasitas Berdasarkan Waktu Pelayanan dan Waktu Transaksi

\section{- Gerbang Tol Kapuk}

Sementara pada Gerbang Tol Kapuk tingkat kedatangan tertinggi $(\lambda)$ adalah 5529 kendaraan/jam. Dari kedatangan tersebut terdapat kedatangan kendaraan yang menggunakan gardu nirsentuh $\left(\lambda_{n}\right)$ sebesar 104 kendaraan/jam, sehingga kedatangan kendaraan untuk GTO dan GSO $\left(\lambda_{\circ}\right)$ adalah 5425 kendaraan/jam. Dengan mengasumsikan tingkat kedatangan kendaraan untuk GTO dan GSO terbagi merata (16 gardu), maka kedatangan kendaraan pada GTO dan GSO per gardu adalah 339 kendaraan/jam. Tingkat pelayanan $(\mu)$ dari masing-masing GTO, GSO, dan Gardu Nirsentuh adalah 330, 289 dan 681 kendaraan/jam. Dari varaibel-variabel tersebut dilakukan analisis, berikut contoh perhitungan analisis model antrian sederhana pada GTO. Berikut ditampilkan hasil analisis antrian dengan metode sederhana pada Tabel 9. 
Tabel 9. Hasil Analisis Perhitungan Model Antrian Sederhana Pada Gerbang Tol Kapuk dengan Menggunakan Kapasitas Berdasarkan Waktu Pelayanan dan Waktu Transaksi

\begin{tabular}{|c|c|c|c|c|c|c|}
\hline \multirow{2}{*}{ No } & \multirow{2}{*}{$\begin{array}{l}\text { Nama } \\
\text { Gardu }\end{array}$} & Ls & $\mathrm{Lq}$ & Ws & $\mathrm{Wq}$ & \multirow{2}{*}{ Keterangan } \\
\hline & & kend & kend & detik & detik & \\
\hline 1 & 2 & 3 & 4 & 5 & 6 & 7 \\
\hline 1 & GTO & $-37,414$ & $-38,441$ & $-0,113$ & $-0,110$ & \multirow{3}{*}{$\begin{array}{c}\text { Kapasitas } \\
\text { Berdasarkan } \\
\text { Waktu Pelayanan }\end{array}$} \\
\hline 2 & GSO & $-6,773$ & $-7,946$ & $-0,023$ & $-0,020$ & \\
\hline 3 & Nirsentuh & 0,087 & 0,007 & 0,000 & 0,001 & \\
\hline 4 & GTO & 0,384 & 0,107 & 0,000 & 0,001 & \multirow{3}{*}{$\begin{array}{c}\text { Kapasitas } \\
\text { Berdasarkan } \\
\text { Waktu Transaksi }\end{array}$} \\
\hline 5 & GSO & 0,535 & 0,186 & 0,001 & 0,002 & \\
\hline 6 & Nirsentuh & 0,087 & 0,007 & 0,000 & 0,001 & \\
\hline
\end{tabular}

\section{IV.5 Model Antrian Lin \& Su}

Dari hasil analisis yang telah dilakukan, ketika menggunakan kapasitas dengan berdasarkan pada waktu transaksi tidak terjadi antrian pada gerbang, hasil ini sama seperti pada perhitungan antrian sederhana. Bila menggunakan kapasitas berdasarkan waktu pelayanan yang merupakan waktu transaksi ditambah dengan koreksi waktu ketika kendaraan masuk dan keluar dari sistem maka hasil yang didapatkan, panjang rata-rata antrian pada Gerbang Tol Cililitan untuk GTO (10 kendaraan) lebih besar dibandingkan dengan Gerbang Tol Kapuk (8 kendaraan). Hal ini berbanding lurus dengan waktu rata-rata dalam antrian yang terjadi. Pada GSO panjang antrian pada Gerbang Tol Cililitan (19 kendaraan) lebih kecil dibandingkan dengan Gerbang Tol Kapuk (27 kendaraan). Dalam hal ini sangat jelas bahwa panjang rata-rata antrian dan waktu rata-rata dalam antrian sangat dipengaruhi oleh nilai $\lambda / \mu$, semakin besar nilai $\lambda / \mu$ maka semakin besar panjang dan waktu rata-rata dalam antrian. Dalam analisis lanjut untuk menghitung nilai waktu hilang kendaraan, waktu dalam antrian yang digunakan berdasarkan kapasitas dengan menggunakan waktu transaksi karena dalam SPM Jalan Tol hanya waktu transaksi yang menjadi standar indikator.

\section{IV.6 Respon Terhadap Penerapan Sistem Pengumpulan Tol Elektronis.}

Respon terhadap penerapan sistem pengumpulan tol elektronis ini ditinjau dari sisi Pengguna Jalan dan Badan Usaha Jalan Tol (BUJT).

\section{- Analisis Persepsi Responden (Pengguna Jalan} Tol)

Respon pengguna jalan tol mengenai penerapan sistem pengumpulan tol elektronis yang ada saat ini dari hasil kuisioner $86 \%$ responden merasa puas, sisanya sebanyak $14 \%$ responden merasa tidak puas karena pernah mengalami masalah ketika melakukan transaksi seperti kartu E-Toll terdebit dua kali dan kartu E-Toll tidak terbaca reader. Sementara tanggapan pengguna jalan mengenai rencana penerapan sistem pengumpulan tol dengan teknologi nirsentuh, sebanyak $92 \%$ responden merasa setuju karena dengan sistem ini dapat mempersingkat waktu transaksi dan tidak lagi terjadi antrian di gerbang. Akantetapi dari $92 \%$ responden yang setuju hanya $23 \%$ responden yang bersedia untuk membeli perangkat OBU dikarenakan harganya yang mahal.

\section{- Analisis Respon Badan Usaha Jalan Tol (BUJT)}

Menurut Badan Usaha Jalan Tol (BUJT) mengenai sistem pengumpulan tol elektronis saat ini, permasalahan yang sering timbul adalah masih banyak pengguna jalan yang saldo E-Toll Card nya kurang sehingga menimbulkan antrian di gerbang, bahkan pada ruas jalan tol Kualanamu sering terjadi pengguna jalan tol yang tidak mempunyai E-Toll Card, hal ini terjadi karena masyarakat di Sumatera khususnya Medan masih banyak yang belum mengetahui jika sekarang ini untuk sistem pembayaran tol dilakukan secara elektronis. Selain itu sesekali terjadi pending settlement HPT di bank penerbit E-Toll Card dan masih ada permasalah dengan integrator terkait proses end to end. .

Tidak hanya kendala saja dengan diterapkannya sistem pengumpulan tol elektronis ini, ada beberapa keuntungan yang diperoleh oleh BUJT. Adapun keuntungan tersebut adalah pengendalian dan monitoring pendapatan tol lebih efisien dan mudah terkontrol, BUJT tidak perlu lagi menyiapkan uang kembalian dan berimbas dengan tidak adanya biaya untuk menyiapkan uang kembalian. Biaya operasional berkurang terutama untuk biaya personil pengumpul tol karena dengan penerapan sistem ini yang awalnya setiap gardu di jaga oleh seorang petugas pengumpul tol, sekarang ini untuk tiga sampai empat gardu di jaga oleh seorang petugas pengumpul tol.

Rikki Sofyan Rizal, Rudy Hermawan K, Titi Liliani S 
Kedepannya BUJT telah melakukan persiapan untuk penerapan transaksi berbasis nirsentuh dengan melakukan koordinasi antar BUJT mengenai sistem dan proses teknologi yang akan diterapkan.

\section{IV.7 Analisis Keuntungan Bagi Badan Usaha Jalan Tol (BUJT) dan Pengguna Jalan Tol Akibat diterapkannya Sistem Pengumpulan Tol Elektronis}

Analisis keuntungan yang akan dihitung yaitu bagi Badan Usaha Jalan Tol (BUJT) dan pengguna jalan tol akibat diterapkannya sistem pengumpulan tol elektronis. Untuk analisis keuntungan BUJT dari datadata yang telah didapatkan maka dibandingkan keuntungan yang didapatkan dari sistem manual dengan sistem elektronis yang ada saat ini. Sementara untuk pengguna jalan akan dilakukan analisis mengenai nilai akumulasi waktu (net saving time value) yang terjadi berdasarkan perbedaan waktu transaksi antara gardu manual dengan gardu elektronis.

\section{- Analisis Keuntungan Bagi Badan Usaha Jalan Tol (BUJT)}

$\bullet$

\section{- Pembangunan Awal}

Dengan diterapkannya sistem pengumpulan tol elektronis ini, biaya investasi untuk gardu elektronis lebih murah khususnya untuk GTO dan GSO bila dibandingkan dengan gardu manual. Jika BUJT membangun sebuah GTO dan GSO maka BUJT akan lehih hemat Rp 217.754.800 dan Rp 123.374.800 dari gardu manual. Sedangkan untuk gardu nirsentuh BUJT harus mengeluarkan biaya yang lebih sebesar Rp 142.499.000 dari gardu manual.

\section{- Biaya operasional}

Biaya operasi pada gardu manual lebih mahal di bandingkan dengan gardu elektronis. Dengan diterapkannya sistem pengumpulan tol elektronis ini BUJT dapat menurunkan biaya untuk personil pengumpul tol sebesar $\mathrm{Rp} 135.180 .000$ pertahun untuk satu buah gardu.

Dengan sistem elektronis saat ini BUJT tidak perlu lagi repot untuk menukarkan dan mengeluarkan biaya uang kembalian sebesar $1 \%$ dari uang yang ditukarkan.
Disisi lain dengan sistem elektronis, BUJT tidak perlu lagi mengeluarkan biaya untuk pengadaan form operasional pengumpul tol sebesar Rp 128.160.000 yang dulu digunakan pengumpul tol untuk mencatat hasil transaksi, karena dengan sistem ini semua kegiatan pengumpulan tol tercatat secara elektronis.

\section{- Biaya Pemeliharaan Periodik}

Dengan diterapkannya sistem pengumpulan tol elektronis, BUJT tidak perlu lagi melakukan pemeliharaan periodik untuk mengganti Kartu Tanda Masuk (KTM) yang rusak atau pun hilang per 3 tahun sebesar Rp 120.000.000, karena pada sistem ini KTM yang dulu digunakan pada gardu manual telah diganti dengan kartu elektronik yang harus dimiliki oleh pengguna jalan. Pada Tabel IV.28 disajikan perbandingan dari masing-masing tipe gardu yang diterapkan

\section{- Analisis Keuntungan Bagi Pengguna Jalan Tol}

Analisis keuntungan bagi pengguna jalan tol ini dilihat dari waktu yang hilang akibat waktu transakis. Nilai waktu yang hilang adalah nilai biaya yang seharusnya tidak dialami oleh kendaraan atau pengguna jalan tol. Nilai waktu hilang dimaksud besarnya tergantung dari nilai waktu pada tahun analisis dikalikan dengan selisih waktu transaksi (T2) antara gardu manual dengan gardu elektronis (GTO, GSO, dan Gardu Nirsentuh).

Besarnya nilai waktu didasarkan pada nilai waktu yang didapatkan dari PT Jasa Marga yaitu Rp 39.995 /jam/kendaraan penumpang. Adapun rata-rata waktu transaksi dari masing-masing tipe gardu adalah 3,0 detik (GTO), 3,6 detik (GSO) dan 0 detik (gardu nirsentuh). Sedangkan untuk waktu transaksi pada gardu manual berdasarkan peneliti terdahulu yaitu 7,8 detik (Mahendra, 2010).

Bila diasumsikan dalam sehari pengguna jalan melintasi gerbang tol sebanyak dua kali dan dalam sebulan pengguna jalan melintasi sebanyak 22 hari, maka didapatkan nilai waktu hilang kendaraan per tahun pada Tabel 10. 
Tabel 10. Hasil Perhitungan Penghematan Nilai Waktu Hilang Kendaraan

\begin{tabular}{|l|l|c|c|c|c|c|}
\hline No & $\begin{array}{c}\text { Tipe } \\
\text { Gardu }\end{array}$ & $\begin{array}{c}\text { Nilai } \\
\text { Waktu } \\
\text { (Waktu } \\
\text { Transaksi) } \\
\text { (Detik) }\end{array}$ & $\begin{array}{c}\Delta \mathrm{T} 2 \\
\text { (Detik) }\end{array}$ & $\begin{array}{c}\text { Nilai } \\
\text { waktu } \\
\text { (Rp)/Kend } \\
\text { /Hari }\end{array}$ & $\begin{array}{c}\text { Nilai } \\
\text { waktu } \\
\text { (Rp)/Kend } \\
\text { /Bulan }\end{array}$ & $\begin{array}{c}\text { Nilai } \\
\text { waktu } \\
\text { (Rp)/Kend } \\
\text { /Tahun }\end{array}$ \\
\hline 1 & Manual & 7,8 & 0,0 & 0 & 0 & 0 \\
\hline 2 & GT0 & 3,0 & 4,8 & 106,65 & $2.346,37$ & $28.156,48$ \\
\hline 3 & GS0 & 3,6 & 4,2 & 93,32 & $2.053,08$ & $24.636,92$ \\
\hline 4 & Nirsentuh & 0,0 & 7,8 & 173,31 & $3.812,86$ & $45.754,28$ \\
\hline
\end{tabular}

Dari hasil analisis, dengan diterapkannya sistem pengumpulan tol elektronis pengguna jalan diuntungkan, karena adanya penghematan nilai waktu hilang bila dibandingkan dengan gardu manual. Adapun penghematan nilai waktu hilang per kendaraan per tahun adalah Rp 28.156,48 (GTO), Rp 24.636,92 (GSO), dan Rp 45.754,28 (Gardu Nirsentuh). Sedangkan untuk pengguna jalan yang melewati gardu nirsentuh dengan penghematan nilai waktu hilang Rp 45.754,28 /kend/tahun, mereka harus membeli perangkat OBU seharga Rp 500.000 untuk bisa melewati gardu tersebut. Harga perangkat OBU tersebut tidak sebanding dengan penghematan nilai waktu hilang yang didapatkan.

\section{KESIMPULAN DAN SARAN}

\section{V.1 Kesimpulan}

Dari analisis yang dilakukan, terdapat beberapa kesimpulan sebagai berikut :

1. Waktu transaksi rata-rata yang terjadi pada GTO dan GSO di Gerbang Tol Cililitan adalah 3,0 detik dan 3,5 detik. Sementara pada Gerbang Tol Kapuk waktu transaksi untuk GTO adalah 2,9 detik dan GSO yaitu 3,7 detik. Dengan demikian waktu transaksi yang terjadi memenuhi SPM Jalan Tol yaitu kurang dari 5 detik.

2. Perhitungan kapasitas rata-rata dengan menggunakan waktu pelayanan pada Gerbang Tol Cililitan dan Gerbang Tol Kapuk adalah 318 kendaraan/jam dan 317 kendaraan/jam sedangkan kapasitas rata-rata dengan menggunakan waktu transaksi adalah 1080 kendaraan/jam pada Gerbang Tol Cililitan dan 1126 kendaraan/jam pada Gerbang Tol Kapuk.

3. Dari hasil perhitungan kapasitas gardu nirsentuh dengan menggunakan metode Greendshield didapatkan kapasitas pada Gerbang Tol Cililitan
1125 kendaraan/jam dan pada Gerbang Tol Kapuk 1097 kendaraan/jam.

4. Hasil model antrian dengan model sederhana maupun model Lin \& Su dengan menggunakan kapasitas berdasarkan waktu transaksi tidak terdapat antrian kendaraan.

5. Respon pengguna jalan tol mengenai penerapan sistem pengumpulan tol elektronis yang ada saat ini dari hasil kuisioner $86 \%$ responden merasa puas. Sementara tanggapan pengguna jalan mengenai rencana penerapan sistem pengumpulan tol dengan teknologi nirsentuh, sebanyak $92 \%$ responden merasa setuju karena dengan sistem ini dapat mempersingkat waktu transaksi dan tidak lagi terjadi antrian di gerbang. Akantetapi dari $92 \%$ responden yang setuju hanya $23 \%$ responden yang bersedia untuk membeli perangkat OBU dikarenakan harganya yang mahal.

6. Menurut Badan Usaha Jalan Tol (BUJT) mengenai sistem pengumpulan tol elektronis saat ini, permasalahan yang sering timbul adalah masih banyaknya pengguna jalan yang saldo E-Toll Card nya kurang, sehingga menimbulkan antrian di gardu. Disisi lain dengan penerapan sistem ini, untuk pengendalian dan monitoring pendapatan tol lebih efisien dan mudah terkontrol. Kedepannya BUJT telah melakukan persiapan untuk penerapan transaksi berbasis nirsentuh dengan melakukan koordinasi antar BUJT mengenai sistem dan proses teknologi yang akan diterapkan.

7. Dengan diterapkannya sistem pengumpulan tol eletronis BUJT mendapatkan beberapa keuntungan dibandingkan dengan sistem pengumpulan tol konvensional seperti biaya pemasangan gardu elektronis yang lebih murah, biaya untuk pengumpul tol semakin berkurang, tidak ada biaya untuk menukarkan uang kembalian, serta tidak perlu melakukan penggantian KTM per 3 tahun.

8. Dengan diterapkannya sistem pengumpulan tol elektronis pengguna jalan mendapatkan penghematan nilai waktu hilang (/kendaraan/tahun) sebesar Rp 28.156,48 (GTO), Rp 24.636,92 (GSO), dan Rp 45.754,28 (Gardu Nirsentuh) dibandingkan dengan gardu manual. Akan tetapi untuk pengguna jalan yang melewati gardu nirsentuh, penghematan nilai waktu hilang yang didapatkan tidak sebanding dengan biaya yang dikeluarkan untuk membeli perangkat OBU seharga Rp 500.000 agar bisa melewati gardu tersebut. 


\section{V.2 Saran}

Setelah melakukan penelitian ini $\mathrm{m}$ beberapa saran sebagai berikut.

1. Untuk penelitian selanjutnya, survey pada Gardu Nirsentuh sebaiknya dilakukan ketika demand kendaraan yang melewati gardu ini sudah cukup banyak, agar pada saat dimodelkan dengan menggunakan model Greenshield, Greendburg, Underwood, atau model lainnya didapatkan hasil yang mendekati dengan kondisi yang terjadi di lapangan.

2. Pada perhitungan kapasitas nirsentuh bila menggunakan model MKJI 1997 perlu ditetapkan asumsi-asumsi yang mendekati kondisi pada gerbang tol agar model hubungan kecepatan-kerapatan-arus didapatkan mendekati dengan kondisi yang terjadi dilapangan.

3. Perlu adanya peningkatan pelayanan dengan penerapan sistem pengumpulan elektronis saat ini seperti meninimalkan atau menghilangkan tidak berfungsinya alat (reader) dengan baik.

\section{REFERENSI}

Hianto, E. (2014): Analisis Kapasitas Gardu Khusus E-Toll Pass (Studi Kasus Culilitan dan Cengkareng), Institut Teknologi Bandung, Bandung.

Karsaman, R. H. (2009): Evaluasi Penerapan Sistem Pengumpulan Tol Elektronis di Indonesia, Institut Teknologi Bandung, Bandung.

Mahendra, Y.Y, (2010): Evaluasi Penerapan Sitem Pengumpulan Tol Elektronis di Indonesia, Magister Tesis, Institut Teknologi Bandung, Bandung

Nugraha, Y.A. (2015): Evaluasi Penerapan dan Perbandingan Sistem Electronic Toll Collection (ETC) di Kota Surabaya, Magister Tesis, Institut Teknologi Bandung, Bandung.

Peraturan Menteri Pekerjaan Umum No 16/PRT/M/2014 tentang Standar Pelayanan Minimal (SPM) Jalan Tol.

Tamin, O.Z. (2008): Perencanaa, Pemodelan dan Rekayasa Transportasi : Teori, Contoh Soal dan Aplikasi, Penerbit ITB, Bandung. 